\title{
Analysis of pre- and intraoperative clinical factors for successful operating room extubation after living donor liver transplantation: a retrospective observational cohort study
}

Min Suk Chae', Jong-Woan Kim', Joon-Yong Jung ${ }^{2}$, Ho Joong Choi ${ }^{3}$, Hyun Sik Chung ${ }^{1}$, Chul Soo Park', Jong Ho Choi ${ }^{1}$ and Sang Hyun Hong ${ }^{1 *}$ (D)

\begin{abstract}
Background: Early extubation after liver transplantation is safe and accelerates patient recovery. Patients with endstage liver disease undergo sarcopenic changes, and sarcopenia is associated with postoperative morbidity and mortality. We investigated the impact of core muscle mass on the feasibility of immediate extubation in the operating room (OR) after living donor liver transplantation (LDLT).

Methods: A total of 295 male adult LDLT patients were retrospectively reviewed between January 2011 and December 2017. In total, 40 patients were excluded due to emergency surgery or severe encephalopathy. A total of 255 male LDLT patients were analyzed in this study. According to the OR extubation criteria, the study population was classified into immediate and conventional extubation groups (39.6 vs. 60.4\%). Psoas muscle area was estimated using abdominal computed tomography and normalized by height squared (psoas muscle index [PMI]).

Results: There were no significant differences in OR extubation rates among the five attending transplant anesthesiologists. The preoperative PMI correlated with respiratory performance. The preoperative PMI was higher in the immediate extubation group than in the conventional extubation group. Potentially significant perioperative factors in the univariate analysis were entered into a multivariate analysis, in which preoperative PMI and intraoperative factors (i.e., continuous renal replacement therapy, significant post-reperfusion syndrome, and fresh frozen plasma transfusion) were associated with OR extubation. The duration of ventilator support and length of intensive care unit stay were shorter in the immediate extubation group than in the conventional extubation group, and the incidence of pneumonia and early allograft dysfunction were also lower in the immediate extubation group.
\end{abstract}

Conclusions: Our study could improve the accuracy of predictions concerning immediate post-transplant extubation in the OR by introducing preoperative PMI into predictive models for patients who underwent elective LDLT.

Keywords: Psoas muscles, Liver transplantation, Airway extubation, Operating rooms

\footnotetext{
* Correspondence: shhong7272@gmail.com

${ }^{1}$ Department of Anesthesiology and Pain medicine, Seoul St. Mary's Hospital,

College of Medicine, The Catholic University of Korea, 222, Banpo-daero,

Seocho-gu, Seoul 06591, Republic of Korea

Full list of author information is available at the end of the article
}

(c) The Author(s). 2019 Open Access This article is distributed under the terms of the Creative Commons Attribution 4.0 International License (http://creativecommons.org/licenses/by/4.0/), which permits unrestricted use, distribution, and

reproduction in any medium, provided you give appropriate credit to the original author(s) and the source, provide a link to the Creative Commons license, and indicate if changes were made. The Creative Commons Public Domain Dedication waiver (http://creativecommons.org/publicdomain/zero/1.0/) applies to the data made available in this article, unless otherwise stated. 


\section{Background}

Patients with end-stage liver disease (ESLD) frequently suffer from sarcopenia, where sarcopenia before liver transplantation (LT) is one of major risk factors for postoperative morbidity and mortality $[1,2]$. A recent study revealed that the degree of perioperative core muscular loss is significantly associated with poor overall patient survival in living donor liver transplantation (LDLT) [3]. Because the model for end-stage liver disease (MELD) score has a limitation in terms of reflecting the physical and nutritional conditions of patients with ESLD, sarcopenia has additional prognostic value for morbidity and mortality in patients with ESLD [4-7]. Particularly, a MELD-Sarcopenia model proved superior to the MELD score in terms of predicting waiting list mortality in LT waiting-list patients with a low MELD score [8].

After LT, prolonged ventilator care with sedation in the intensive care unit (ICU) has been the typical postoperative management strategy [9]. However, studies of other surgeries showed that early tracheal extubation has favorable effects on postoperative patient recovery [10, 11]. Additionally, because the use of ventilator support in the ICU accounts for a large proportion of LT costs, successful early extubation may effectively reduce the financial burden [12]. However, although there is much evidence that early extubation after LT is a safe and feasible practice [12-18], many transplant centers still use routine mechanical ventilation in the ICU after LT. Because LT surgery is one of the most complex procedures currently performed, some transplant clinicians remain concerned regarding the potential risk of cardiopulmonary complications, reoperation, failed extubation, and impaired recovery from surgical stress [13, 19], despite the identification in previous studies of predictors of early extubation in the operating room (OR) after LT $[14,15]$.

The aim of this study was to investigate the association between pre- and intraoperative factors, including core muscle mass, and immediate extubation in the OR after LDLT. In addition, we compared short-term postoperative complications and outcomes according to OR extubation.

\section{Patients and methods}

\section{Ethical considerations}

The Institutional Review Board of Seoul St. Mary's Hospital Ethics Committee approved this study for LDLT recipients (KC18RESI0205) on April 13, 2018, and it was performed according to the principles of the Declaration of Helsinki. The requirement for informed consent was waived due to the retrospective study design.

\section{Inclusion and exclusion criteria}

The inclusion criteria were 1) male; 2) adult (age $\geq 19$ years); and 3) patients who underwent elective LDLT.
The clinical exclusion criteria were 1) emergency LDLT and 2) severe encephalopathy (West-Haven criteria III or IV) [20], because patients with those conditions underwent routine mechanical ventilation after surgery to protect the airway from pulmonary aspiration. Recipients or donors whose electronic medical records contained defective or missing data were also excluded.

\section{Living donor liver transplantation}

Surgery and anesthesia were consistently provided by expert transplant surgeons and anesthesiologists with $>5$ years' experience in LDLT, respectively. The surgical procedure and anesthetic management were described in detail in our previous studies [3, 21, 22]. Briefly, the piggyback technique was performed using the right liver lobe with reconstruction of the middle hepatic vein. Following the hepatic vessel and bile duct anastomoses, patency of the hepatic vessels was confirmed by Doppler ultrasonography.

Balanced anesthesia was performed under multiple invasive monitoring. The optimal hemodynamic adjustment was made with a mean arterial pressure (MAP) of $\geq 65$ $\mathrm{mmHg}$ and a central venous pressure of $\leq 10 \mathrm{mmHg}$. According to the Practice Guidelines for Perioperative Blood Management [23], packed red blood cells (PRBCs) were transfused to a hematocrit level of $\geq 25 \%$, and coagulation factors were replaced as determined by laboratory assessment or thromboelastography (Thromboelastograph Model 5000; Haemoscope Corporation, Niles, IL, USA) [24]. The kidney function of patients who scheduled elective LDLT was regularly monitored by nephrologists, and patients with severely decreased kidney function before surgery (an increase in serum creatinine to $\geq 4.0 \mathrm{mg} \cdot \mathrm{dL}^{-1}$ or to 3 -fold baseline level, a urine output of $\leq 0.3 \mathrm{~mL} \cdot \mathrm{kg}^{-1} \cdot \mathrm{h}^{-1}$ for $24 \mathrm{~h}$, or anuria for $12 \mathrm{~h}$ ) were intraoperatively given continuous renal replacement therapy (CRRT) (PRISMAFLEX System; Baxter) [25-27]. The expert transplant anesthesiologists classified postreperfusion syndrome (PRS) as significant, immediately after graft reperfusion, when unstable and persistent vital signs (i.e., hypotension $\geq 30 \%$ in the anhepatic phase or hypotensive duration $\geq 5 \mathrm{~min}$ ); fatal arrhythmias (i.e., asystole or ventricular tachycardia); requirement for strong rescue vasopressors (i.e., epinephrine or norepinephrine infusion); continuing or reoccurring fibrinolysis; or a requirement for an anti-fibrinolytic drug were present [28].

An immunosuppression regimen (calcineurin inhibitor, mycophenolate mofetil, and prednisolone) was applied according to the hospital LDLT protocol. Basiliximab was administered before transplant surgery and 4 days after the surgery. The immunosuppressive drugs were progressively discontinued after LDLT. 
Criteria for immediate extubation in the operating room Immediate extubation was defined as tracheal extubation in the OR at the end of surgery, and conventional extubation was defined as tracheal extubation in the ICU. The five attending anesthesiologists (M.S.C.; H.S.C.; C.S.P.; J.H.C.; S.H.H.), who specialized in anesthetic management for LT, decided whether to extubate patients in the OR, immediately after surgery, based on standardized and universally accepted criteria: adequate oxygenation $\left(\mathrm{SpO}_{2} \geq 95 \%\right.$, with $\mathrm{FiO}_{2} \leq 0.5$ ); adequate ventilation (tidal volume $\geq 5 \mathrm{~mL} . \mathrm{kg}^{-1}$ and spontaneous respiration rate $<25 \mathrm{~min}^{-1}$ with normocarbia $\left[\mathrm{ETCO}_{2} \quad 30-40 \mathrm{mmHg}\right]$ ); stable hemodynamic condition or minimal use of a vasopressor (norepinephrine infusion $<0.1 \mu \mathrm{g} \cdot \mathrm{kg}^{-1} \cdot \mathrm{min}^{-1}$ ); full clinical reversal of muscle relaxation (sustained head lift for $5 \mathrm{~s}$ or hand grasp); neurologically intact condition (able to follow simple verbal orders, spontaneous eye opening, and proper cough/ gag reflex); appropriate metabolic status $(\mathrm{pH}>7.25$, normal electrolytes, and euvolemia); normothermia $\left(\geq 35.5^{\circ} \mathrm{C}\right)$; and no surgical concerns regarding ongoing bleeding or hepatic vascular patency $[12,15,17]$. The surgeon was not consulted unless a surgical issue arose. All patients were transferred to the ICU after surgery.

The patients were classified into two groups: those who were extubated in the OR were classified into the immediate extubation group and those who were not extubated in the OR were classified into the conventional extubation group.

\section{Measurement of psoas muscle area}

The abdominal condition of patients who were scheduled for elective LDLT was routinely investigated using computed tomography (CT) within 1 month prior to surgery.

The cross-sectional areas of both PMAs between lumbar vertebrae 3 and 4 were manually evaluated on abdominal CT images (PACS Viewer; INFINITT Healthcare Co., Ltd., Phillipsburg, NJ, USA) using a two-dimensional module, with intramuscular fatty infiltration removed from the PMA images using automated software (AQI; TeraRecon, Foster City, CA, USA). The average of the two PMAs was estimated and normalized to the patient's height squared $\left(\mathrm{PMI}=\mathrm{PMA}\right.$.height $\left.{ }^{-2}\right)$. The abdominal CT images were analyzed by a radiologist (J.Y.J.) with 10 years' experiences who was blinded to the clinical data.

In this study, the PMI was considered a core muscle index in patients who underwent elective $\operatorname{LDLT}[3,29,30]$.

\section{Correlations between respiratory performance and preoperative PMI}

We studied the correlations between respiratory performance using preoperative spirometry parameters (i.e., forced vital capacity [FVC], the first second of forced expiration $\left[\mathrm{FEV}_{1}\right]$, and forced expiratory flow $[\mathrm{FEF}]$ ) and preoperative PMI.

\section{Perioperative recipient and donor-graft factors}

Preoperative recipient findings included age, body mass index (BMI), etiology of ESLD, comorbidities (diabetes mellitus $[\mathrm{DM}]$, systemic hypertension [HBP], diseases of the heart and kidney, lung disease determined by symptoms of dyspnea with atelectasis, consolidation, or pleural effusion using chest X-ray or CT images, smoking status, history of abdominal surgery, MELD score, complications of ESLD (mild encephalopathy [West-Haven grade I or II] [20], varix, and ascites $[>1 \mathrm{~L}]$ ), transthoracic echocardiography (ejection fraction and diastolic dysfunction), and laboratory findings (hematocrit, creatinine, total bilirubin, sodium, potassium, albumin, ammonia, glucose, international normalized ratio [INR], and platelet count). Intraoperative recipient findings included surgical duration, CRRT, administration of a strong vasopressor (i.e., norepinephrine infusion $\geq 0.1 \mu \mathrm{g} \cdot \mathrm{kg}^{-1} \cdot \mathrm{min}^{-1}$ ), significant PRS [28], hourly fluid infusion, hourly urine output, total amount of blood product transfused (PRBCs, fresh frozen plasma [FFP], platelet concentrate $[\mathrm{PC}]$, single donor platelets [SDPs], and cryoprecipitate), mean laboratory values (lactate, glucose, and brain natriuretic peptide $[\mathrm{BNP}])$, and mean arterial blood gas analysis values $(\mathrm{pH}$, hemoglobin, $\mathrm{PaO}_{2}, \mathrm{SaO}_{2}$, and $\mathrm{PaCO}_{2}$ ). Donor-graft findings included age, sex, BMI, graft-recipient weight ratio (GRWR), steatosis, and total graft ischemic time.

\section{Clinical postoperative outcomes}

Clinical postoperative outcomes included duration of ventilator support, and the incidence of re-intubation, pneumonia and early allograft dysfunction (EAD) in the ICU. EAD was defined as the presence of one or more of the following: total bilirubin $\geq 10 \mathrm{mg} \cdot \mathrm{dL}^{-1}$ or INR $\geq 1.6$ on postoperative day 7; and AST or ALT $\geq 2000 \mathrm{IU}_{\mathrm{mL}}{ }^{-1}$ during the first week [31]. The total lengths of the ICU and hospital stays were compared between the immediate and conventional extubation groups.

\section{Statistical analysis}

The perioperative recipient and donor-graft factors were compared between the immediate extubation and conventional groups using the Mann-Whitney $U$ test and the $\chi^{2}$ test. The normality of the distribution of continuous data was analyzed using the Shapiro-Wilk test. The OR extubation rates were compared among five expert anesthesiologists using the $\chi^{2}$ test. The correlations of spirometry parameters and preoperative PMI were evaluated using Spearman's method. Perioperative factors affecting immediate extubation in the OR were analyzed using univariate and multivariate logistic regression. Significant factors $(p<0.1)$ in the univariate analysis were entered into the forward and backward multivariate analyses. The most relevant clinical factors were determined when multiple perioperative factors were correlated. The 
PMIs were compared between the two groups using the Mann-Whitney $U$ test. In addition, the accuracy of the predictive model was analyzed using the area under the receiver operating characteristic curve (AUC). An optimal cut-off value of preoperative PMI according to OR extubation was determined using the AUC method. Values are expressed as means \pm standard deviation (SD), medians and interquartile ranges (IQR), or as numbers and proportions. All tests were two-sided, and a $p$-value $<0.05$ was considered significant. Statistical analyses were conducted using SPSS for Windows (ver. 24.0; SPSS Inc., Chicago, IL, USA) and MedCalc for Windows software (ver. 11.0; MedCalc Software, Ostend, Belgium). The TRIPOD reporting guidelines were followed during the development of the prediction model, and in the validation study [32].

\section{Results}

\section{Baseline characteristics of the study population}

The initial study population consisted of 295 male adult patients (age $\geq 19$ years) who underwent LDLT at our hospital between January 2011 and December 2017. After removing 40 patients based on the exclusion criteria, 255 male patients who underwent elective LDLT remained. The average age of the patients was $52 \pm 8$ years and the BMI was $24.8 \pm 3.6 \mathrm{~kg} \cdot \mathrm{m}^{-2}$. The most common etiology was hepatitis B $(66.3 \%)$, followed by alcohol (20.8\%), hepatitis C (5.5\%), toxin or drug (3.9\%), hepatitis A (1.2\%), autoimmune (0.4\%), and cryptogenic hepatitis (2.0\%). The median (IQR) MELD score was 13 (8-21) points and hepatic decompensation signs were as follows: ascites $>1 \mathrm{~L}(41.2 \%)$, encephalopathy (WestHaven grade I or II) (27.1\%), varix (23.5\%), and hepatorenal syndrome $(12.2 \%)$. The average preoperative PMI was $359.4 \pm 95.8 \mathrm{~mm}^{2} \cdot \mathrm{m}^{-2}$. In total, 101 of 255 patients $(39.6 \%)$ were extubated in the OR immediately after surgery. There were no significant differences in OR extubation rate among the attending transplant anesthesiologists (Additional file 1).

Based on OR extubation, the optimal cut-off value of preoperative PMI was $352.2 \mathrm{~mm}^{2} \cdot \mathrm{m}^{-2}$ (AUC: 0.862; 95\% confidence interval: $0.814-0.902 ; p<0.001)$. Thus, 125 patients (49.0\%) had non-sarcopenic features and 130 (51.0\%) showed sarcopenic features (Additional file 2).

\section{Correlation between respiratory performance and preoperative PMI}

Additional file 3 shows that preoperative PMI was weakly correlated with respiratory performance parameters, such as FVC (L), FVC (\%), $\mathrm{FEV}_{1}$ (L),

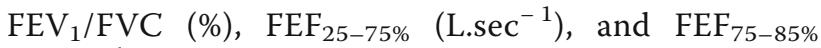
$\left({\mathrm{L} . \mathrm{sec}^{-1}}^{1}\right.$ ). Only $\mathrm{FEV}_{1}$ (\%) was moderately correlated with the PMI.
Comparison of clinical characteristics between the immediate and conventional extubation groups The preoperative recipient findings differed between the two groups, including with respect to $\mathrm{BMI}$; incidence of lung disease; MELD score; the incidence rates of encephalopathy (West-Haven grade I or II) and ascites $(>1 \mathrm{~L})$; and the levels of hematocrit, sodium, albumin, platelets, total bilirubin and INR (Table 1).

The intraoperative recipient findings of the two groups also differed, in terms of surgical duration; frequency of administration of a strong vasopressor; incidence of significant PRS; hourly fluid infusion and urine output; requirement for blood products transfusion (i.e., PRBCs, FFP, PC, SDPs and cryoprecipitates); and the levels of BNP and hemoglobin (Table 2). Although $\mathrm{SaO}_{2}$ was lower in the immediate extubation group than in the conventional extubation group, the range of $\mathrm{SaO}_{2}$ was within normal limits $(\geq 94 \%)$ in both groups [33]. Despite differences in the donor-graft findings, such as total graft ischemic time and GRWR, all transplant recipients received a graft of sufficient size (GRWR $\geq 0.8)$ [34].

Preoperative PMI (median and IQR) was significantly higher in the immediate extubation group than in the conventional extubation group: $309.0(259.6-352.7) \mathrm{mm}^{2} . \mathrm{m}^{-2}$ vs. $414.9(367.7-480.0) \mathrm{mm}^{2} \cdot \mathrm{m}^{-2}$ in the immediate extubation group (Fig. 1).

\section{Predictive factors for immediate extubation in the operating room}

Table 3 suggests an association between perioperative recipient and donor-graft findings and immediate extubation in the OR among male patients who underwent elective LDLT. After an analysis of the potentially significant preoperative and intraoperative recipient and donorgraft findings in a multivariate logistic regression, the model revealed that preoperative PMI and intraoperative factors (i.e., use of CRRT, development of significant PRS, and FFP transfusion requirement) were independently associated with immediate extubation in the OR (AUC: 0.914; $95 \%$ confidence interval: $0.88-0.949 ; p<0.001$ in the predictive model).

\section{Comparison of postoperative outcomes between the immediate and conventional extubation groups}

The length of ICU stay and duration of ventilator support were shorter in the immediate extubation group than in the conventional extubation group, and the incidence of pneumonia and EAD were also lower in the immediate extubation group (Table 4). Three patients in the immediate extubation group underwent re-intubation in the ICU. The causes of re-intubation in the immediate extubation group were development of graft dysfunction $(n=2$ patients) and respiratory distress due to pneumonia 
Table 1 Comparison of preoperative recipient findings between the conventional and immediate extubation groups

\begin{tabular}{|c|c|c|c|}
\hline Group & Conventional extubation & Immediate extubation & $p$ \\
\hline$n$ & 154 & 101 & \\
\hline \multicolumn{4}{|l|}{ Preoperative recipient findings } \\
\hline Age (year) & $53(47-59)$ & $54(49-57)$ & 0.983 \\
\hline Body mass index $\left(\mathrm{kg} \cdot \mathrm{m}^{-2}\right)$ & $23.9(21.9-26.6)$ & $24.9(23.2-26.7)$ & 0.016 \\
\hline \multicolumn{4}{|l|}{ Etiology of end-stage liver disease } \\
\hline Alcohol & $33(21.4 \%)$ & $20(19.8 \%)$ & \\
\hline Hepatitis A & $2(1.3 \%)$ & $1(1.0 \%)$ & \\
\hline Hepatitis B & $98(63.6 \%)$ & $71(70.3 \%)$ & \\
\hline Hepatitis C & $11(7.1 \%)$ & $3(3.0 \%)$ & \\
\hline Autoimmune & $0(0.0 \%)$ & $1(1.0 \%)$ & \\
\hline Toxin \& drug & $7(4.5 \%)$ & $3(3.0 \%)$ & \\
\hline Cryptogenic & $3(1.9 \%)$ & $2(2.0 \%)$ & \\
\hline \multicolumn{4}{|l|}{ Comorbidity } \\
\hline Diabetes mellitus & $42(27.3 \%)$ & 19 (18.8\%) & 0.121 \\
\hline Systemic hypertension & $32(20.8 \%)$ & $17(16.8 \%)$ & 0.434 \\
\hline Heart disease & $7(4.5 \%)$ & $1(1.0 \%)$ & 0.152 \\
\hline Lung disease & $25(16.2 \%)$ & $7(6.9 \%)$ & 0.028 \\
\hline Kidney disease & $19(12.3 \%)$ & $6(5.9 \%)$ & 0.093 \\
\hline Current smoker & $34(22.1 \%)$ & $20(19.8 \%)$ & 0.664 \\
\hline History of abdominal surgery & $33(21.4 \%)$ & $13(12.9 \%)$ & 0.082 \\
\hline Model for end-stage liver disease (pts) & $16(10-26)$ & $9(7-14)$ & $<0.001$ \\
\hline \multicolumn{4}{|l|}{ Complications of end-stage liver disease } \\
\hline Mild encephalopathy & $50(32.5 \%)$ & $19(18.8 \%)$ & 0.016 \\
\hline Varix & $40(26.0 \%)$ & $20(19.8 \%)$ & 0.256 \\
\hline Ascites (> $1 \mathrm{~L}$ ) & $73(47.4 \%)$ & $32(31.7 \%)$ & 0.013 \\
\hline \multicolumn{4}{|l|}{ Transthoracic echocardiography } \\
\hline Ejection fraction (\%) & $64.5(62.0-67.9)$ & $64.8(62.0-67.0)$ & 0.656 \\
\hline Diastolic dysfunction & $52(33.8 \%)$ & $28(27.7 \%)$ & 0.379 \\
\hline \multicolumn{4}{|l|}{ Laboratory findings } \\
\hline Hematocrit (\%) & $28.3(24.4-33.9)$ & $32.7(26.6-38.2)$ & $<0.001$ \\
\hline Creatinine $\left(\mathrm{mg}_{\mathrm{dL}} \mathrm{dL}^{-1}\right)$ & $0.8(0.7-1.2)$ & $0.8(0.7-0.9)$ & 0.199 \\
\hline Total bilirubin (mg.dL ${ }^{-1}$ ) & $3.4(1.0-14.5)$ & $1.6(0.7-4.2)$ & 0.002 \\
\hline Sodium (mEq.L L $^{-1}$ ) & $138.0(133.8-141.0)$ & $141.0(138.0-142.0)$ & $<0.001$ \\
\hline Potassium (mEq..-1 ${ }^{-1}$ ) & $4.0(3.7-4.3)$ & $4.0(3.8-4.3)$ & 0.95 \\
\hline Albumin $\left(\mathrm{g} \cdot \mathrm{dL}^{-1}\right)$ & $2.9(2.7-3.5)$ & $3.2(2.7-3.7)$ & 0.015 \\
\hline Ammonia $\left(\mu \mathrm{g} \cdot \mathrm{dL}^{-1}\right)$ & $98.0(65.0-159.0)$ & $121.0(73.3-178.0)$ & 0.147 \\
\hline Glucose $\left(m g \cdot d L^{-1}\right)$ & $113.5(93.8-139.0)$ & $101.0(91.0-129.0)$ & 0.053 \\
\hline International normalized ratio & $1.6(1.3-2.1)$ & $1.4(1.2-1.7)$ & 0.004 \\
\hline Platelet count $\left(\times 10^{9} \cdot \mathrm{L}^{-1}\right)$ & $58.5(42.0-87.3)$ & $73.0(48.0-124.0)$ & 0.003 \\
\hline
\end{tabular}

Values are expressed as medians (with interquartile range) or numbers (with \% proportion)

( $n=1$ patient). A total of 10 patients in the conventional extubation group had re-intubation due to graft dysfunction ( $n=3$ patients), respiratory distress related to pneumonia ( $n=5$ patients), and miscellaneous reasons ( $n=2$ patients).

\section{Discussion}

The main finding of this study was that preoperative PMI was an independent predictor of immediate extubation in the OR after elective LDLT, together with CRRT, significant 
Table 2 Comparison of intraoperative recipient and graft-donor findings between the conventional and immediate extubation groups

\begin{tabular}{|c|c|c|c|}
\hline Group & Conventional extubation & Immediate extubation & $p$ \\
\hline $\mathrm{n}$ & 154 & 101 & \\
\hline \multicolumn{4}{|l|}{ Intraoperative recipient finding } \\
\hline Surgical duration (min) & $515(464-586)$ & $490(450-556)$ & 0.031 \\
\hline Continuous renal replacement therapy & $13(8.4 \%)$ & $3(3.0 \%)$ & 0.078 \\
\hline${ }^{\mathrm{a} S t r o n g ~ v a s o p r e s s o r ~ a d m i n i s t r a t i o n ~}$ & $38(24.7 \%)$ & $11(10.9 \%)$ & 0.006 \\
\hline Significant postreperfusion syndrome & $41(26.6 \%)$ & $5(5.0 \%)$ & $<0.001$ \\
\hline Hourly fluid infusion (mL.kg $\left.{ }^{-1} \cdot \mathrm{h}^{-1}\right)$ & $10.9(7.9-13.7)$ & $9.3(6.7-11.8)$ & 0.001 \\
\hline Hourly urine output $\left(\mathrm{mL} . \mathrm{kg}^{-1} \cdot \mathrm{h}^{-1}\right)$ & $1.2(0.6-2.0)$ & $1.6(0.9-2.3)$ & 0.002 \\
\hline \multicolumn{4}{|c|}{ Total amount of blood product transfusion during surgery (unit) } \\
\hline Packed red blood cell & $9(5-15)$ & $4(2-8)$ & $<0.001$ \\
\hline Fresh frozen plasma & $10(5-13)$ & $5(3-7)$ & $<0.001$ \\
\hline Platelet concentrate & $0(0-6)$ & $0(0-0)$ & $<0.001$ \\
\hline Single donor platelet & $0(0-1)$ & $0(0-0)$ & 0.003 \\
\hline Cryoprecipitate & $0(0-0)$ & $0(0-0)$ & 0.001 \\
\hline \multicolumn{4}{|c|}{ Average of laboratory factors during entire surgery } \\
\hline Lactate $\left(\mathrm{mmol} . \mathrm{L}^{-1}\right)$ & $4.4(3.2-5.6)$ & $4.2(3.6-5.4)$ & 0.85 \\
\hline Glucose $\left(m g \cdot d L^{-1}\right)$ & $183(156-206)$ & $187(163-206)$ & 0.624 \\
\hline Brain natriuretic peptide $\left(\mathrm{pg} \cdot \mathrm{mL}^{-1}\right.$ ) & $83(40-172)$ & $59(31-103)$ & 0.027 \\
\hline \multicolumn{4}{|l|}{ Average of $A B G A$ factors during entire surgery } \\
\hline $\mathrm{pH}$ & $7.32(7.28-7.37)$ & $7.34(7.31-7.38)$ & 0.055 \\
\hline Hemoglobin $\left(g \cdot \mathrm{dL}^{-1}\right)$ & $9.5(8.7-10.2)$ & $10.5(9.7-11.5)$ & $<0.001$ \\
\hline $\mathrm{PaO}_{2}(\mathrm{mmHg})$ & $189.4(160.8-222.5)$ & $187.0(163.4-216.4)$ & 0.971 \\
\hline $\mathrm{SaO}_{2}(\%)$ & $99.4(99.0-99.6)$ & $99.2(98.8-99.5)$ & 0.01 \\
\hline $\mathrm{PaCO}_{2}(\mathrm{mmHg})$ & $36.0(34.9-37.2)$ & $36.0(34.1-37.4)$ & 0.76 \\
\hline \multicolumn{4}{|l|}{ Donor-graft findings } \\
\hline Age (year) & $33(25-46)$ & $32(24-43)$ & 0.923 \\
\hline Sex (Male) & $89(57.8 \%)$ & $66(65.3 \%)$ & 0.227 \\
\hline Body mass index $\left(\mathrm{kg} \cdot \mathrm{m}^{-2}\right)$ & $23.5(22.1-25.1)$ & $23.4(21.0-25.0)$ & 0.285 \\
\hline Graft-recipient weight ratio & $1.2(1.0-1.5)$ & $1.1(1.0-1.3)$ & 0.019 \\
\hline Steatosis (\%) & $5.0(0.0-5.0)$ & $3.0(0.0-5.0)$ & 0.463 \\
\hline Steatosis type & & & 0.264 \\
\hline None & $51(33.1 \%)$ & $30(29.7 \%)$ & \\
\hline Microvesicular & $13(8.4 \%)$ & $3(3.0 \%)$ & \\
\hline Macrovesicular & $81(52.6 \%)$ & $62(61.4 \%)$ & \\
\hline Mixed & $9(5.8 \%)$ & $6(5.9 \%)$ & \\
\hline Total graft ischemic time (min) & $107(74-147)$ & $90(66-113)$ & 0.001 \\
\hline
\end{tabular}

Values are expressed as medians (with interquartile range) or numbers (with \% proportion) Abbreviation: $A B G A$ arterial blood gas analysis

${ }^{a}$ Strong vasopressor administration is defined as norepinephrine infusion $\geq 0.1 \mu \mathrm{g} \cdot \mathrm{kg}^{-1} \cdot \mathrm{min}^{-1}$

PRS and a large FFP transfusion. The PMI value was higher in the immediate extubation group than in the conventional extubation group. Based on the standardized and universally accepted criteria for endotracheal extubation, the predictive accuracy of our model for OR extubation was high.
In our study, preoperative PMI positively correlated with respiratory performance quantified by spirometry parameters (i.e., $\mathrm{FVC}, \mathrm{FEV}_{1}, \mathrm{FEF}_{25-75 \%}$, and $\mathrm{FEF}_{75-85 \%}$ ). This finding was supported by recent studies showing that preoperative muscular quantity and quality parameters (i.e., PMI and intramuscular adipose content 


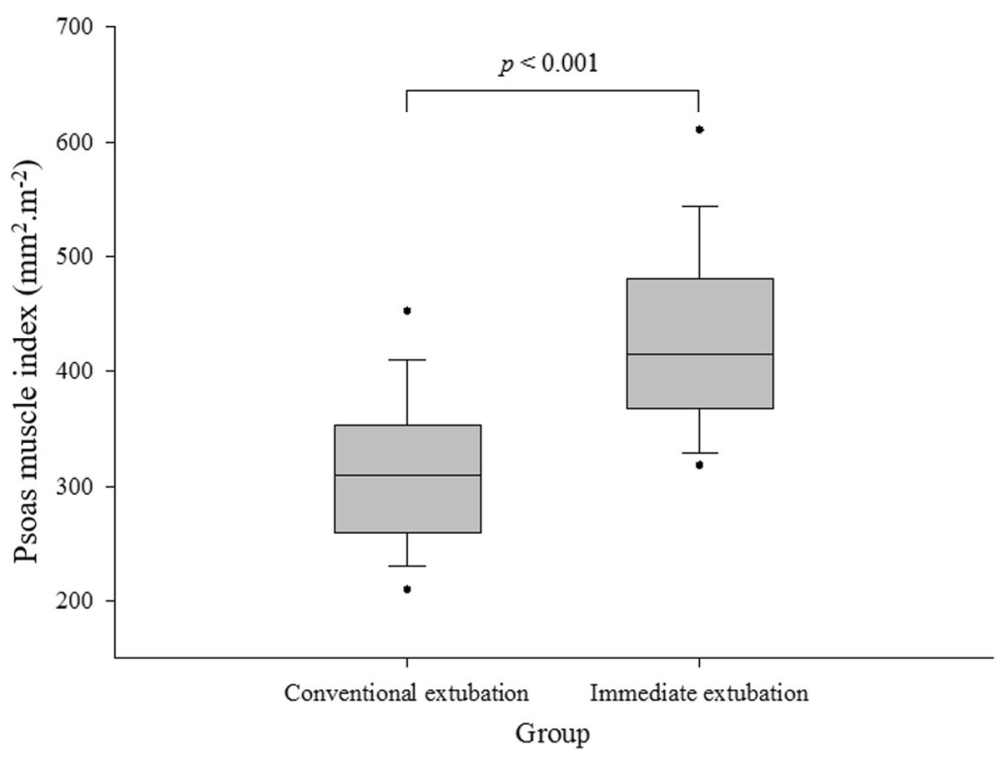

Fig. 1 Comparison of preoperative psoas muscle index between the conventional extubation and immediate extubation groups in male patients who underwent elective living donor liver transplantation (LDLT). The box plots show the median (line in the middle of the box), interquartile range (box), 5th and $9^{5}$ th percentiles (whiskers), and outliers (dots)

[IMAC]) are associated with preoperative respiratory function parameters (i.e., vital capacity $[\mathrm{VC}]$ and $\mathrm{FEV}_{1}$ ) in patients who underwent hepatectomy for liver cancer [35]. In male patients who underwent LDLT, preoperative levels of PMI and IMAC, as well as grip strength (GS) were associated with preoperative $\mathrm{VC}$ and $\mathrm{FEV}_{1}$. In female patients, preoperative levels of IMAC and GS were associated with preoperative $\mathrm{VC}$ and $\mathrm{FEV}_{1}$ [29]. These studies suggested that patients with low muscular quantity and quality had poorer respiratory function than those with normal muscular quantity and quality $[29,35]$.

Our LDLT study suggested that increased preoperative core muscle mass (i.e., PMI) significantly increased the feasibility of OR extubation after elective surgery. Based on the standardized and universally accepted criteria for endotracheal extubation, sufficient core muscle mass before surgery seems to guarantee the recovery and maintenance of patient respiratory capacity immediately after surgery and improves the success rate of OR extubation without fatal complications. LDLT patients who are eligible for successful OR extubation may have sufficient physiological reserves to maintain homeostasis in the presence of external stress (i.e., surgery) whereas a low preoperative core muscle mass may be a marker of an increased risk of failed OR extubation [5, 36, 37]. In a surgical ICU study, muscle weakness in the extremities, measured as the ability to move against gravity and/or resistance, was associated with a higher re-intubation rate following extubation, with the additional consequences of prolonged mechanical support and weaning failure [38]. The MELD score is of limited value in reflecting the nutritional and functional condition of patients with ESLD, and preoperative core muscle mass measurements may help to identify patients suitable for immediate OR extubation, preventing unnecessary ventilator support after transplantation surgery $[1,5-7,13,39]$.

Many studies have focused on preoperative hepatic decompensation or intraoperative hemodynamic instability for predicting early extubation after LT $[14,15,18]$, and our results also show that intraoperative factors related to hemodynamic disturbance (i.e., the use of CRRT, the occurrence of significant PRS, and a requirement for a large FFP transfusion) were negatively associated with immediate extubation in the OR. A prospective study by Biancofiore et al. [14] suggested that patients suitable for immediate postoperative extubation were predominantly male, and that a MELD score of 11 points was the optimal cut-off for immediate postoperative extubation. The immediate postoperative extubation group suffered less severe intraoperative hemorrhage and showed a lower requirement for blood product transfusion than the nonextubation group. Immediately after liver graft reperfusion, patients in the immediate extubation group experienced low blood pressure that required a vasopressor less frequently than those in the non-extubation group. Skurzak et al. [18] devised a prognostic score for early extubation in the OR after LT that consisted of two major factors (intraoperative PRBC transfusion $\geq 7$ units and lactate level $\geq 3.4 \mathrm{mmol} \cdot \mathrm{L}^{-1}$ at the end of surgery) and three minor factors (home vs. hospitalized patients before LT; surgical duration $\geq 5 \mathrm{~h}$; and dopamine $\geq 5 \mu \mathrm{g} \cdot \mathrm{kg}^{-1} \cdot \mathrm{min}^{-1}$ or norepinephrine $\geq 0.05 \mu \mathrm{g} \cdot \mathrm{kg}^{-1} \cdot \mathrm{min}^{-1}$ 
Table 3 Association of perioperative recipient and donor-graft factors with early extubation in operating room in male patients undergoing elective living donor liver transplantation

\begin{tabular}{|c|c|c|c|c|c|c|c|c|}
\hline & \multicolumn{4}{|c|}{ Univariate logistic regression } & \multicolumn{4}{|c|}{ Multivariate logistic regression } \\
\hline & $\bar{\beta}$ & OR & $95 \% \mathrm{Cl}$ & $p$ & $\bar{\beta}$ & OR & $95 \% \mathrm{Cl}$ & $p$ \\
\hline \multicolumn{9}{|l|}{ Preoperative recipient findings } \\
\hline Body mass index $\left(\mathrm{kg} \cdot \mathrm{m}^{-2}\right)$ & 0.067 & 1.069 & $0.997-1.146$ & 0.061 & & & & \\
\hline Psoas muscle index $\left(\mathrm{mm}^{2} \cdot \mathrm{m}^{-2}\right)$ & 0.02 & 1.02 & $1.015-1.025$ & $<0.001$ & 0.025 & 1.025 & $1.017-1.033$ & $<0.001$ \\
\hline Lung disease & -0.956 & 0.384 & $0.16-0.926$ & 0.033 & & & & \\
\hline History of abdominal surgery & -0.613 & 0.542 & $0.27-1.089$ & 0.085 & & & & \\
\hline Model for end-stage liver disease (pts) & -0.089 & 0.915 & $0.884-0.948$ & $<0.001$ & & & & \\
\hline \multicolumn{9}{|l|}{ Complications of end-stage liver disease } \\
\hline Mild Encephalopathy & -0.73 & 0.482 & $0.264-0.88$ & 0.018 & & & & \\
\hline Ascites (> $1 \mathrm{~L}$ ) & -0.664 & 0.515 & $0.304-0.87$ & 0.013 & & & & \\
\hline \multicolumn{9}{|l|}{ Laboratory findings } \\
\hline Hematocrit (\%) & 0.07 & 1.072 & $1.032-1.114$ & $<0.001$ & & & & \\
\hline Total bilirubin (mg.dL ${ }^{-1}$ ) & -0.047 & 0.954 & $0.927-0.983$ & 0.002 & & & & \\
\hline Sodium (mEq. $\mathrm{L}^{-1}$ ) & 0.088 & 1.091 & $1.035-1.151$ & 0.001 & & & & \\
\hline Ammonia $\left(\mu \mathrm{g} \cdot \mathrm{dL}^{-1}\right)$ & 0.003 & 1.003 & $0.999-1.006$ & 0.097 & & & & \\
\hline International normalized ratio & -0.762 & 0.467 & $0.289-0.754$ & 0.002 & & & & \\
\hline Platelet count $\left(\times 10^{9} \cdot \mathrm{L}^{-1}\right)$ & 0.006 & 1.006 & $1.002-1.011$ & 0.007 & & & & \\
\hline \multicolumn{9}{|l|}{ Intraoperative recipient finding } \\
\hline Surgical duration (min) & -0.003 & 0.997 & $0.995-1.000$ & 0.08 & & & & \\
\hline Continuous renal replacement therapy & -1.103 & 0.332 & $0.092-1.196$ & 0.092 & -3.781 & 0.023 & $0.002-0.301$ & 0.004 \\
\hline Strong vasopressor administration & -0.986 & 0.373 & $0.181-0.771$ & 0.008 & & & & \\
\hline Significant postreperfusion syndrome & -1.941 & 0.144 & $0.055-0.378$ & $<0.001$ & -1.781 & 0.168 & $0.043-0.654$ & 0.01 \\
\hline Hourly fluid infusion $\left(\mathrm{mL} . \mathrm{kg}^{-1} \cdot \mathrm{h}^{-1}\right)$ & -0.105 & 0.901 & $0.847-0.958$ & 0.001 & & & & \\
\hline Hourly urine output $\left(\mathrm{mL} \cdot \mathrm{kg}^{-1} \cdot \mathrm{h}^{-1}\right)$ & 0.306 & 1.358 & $1.079-1.708$ & 0.009 & & & & \\
\hline \multicolumn{9}{|c|}{ Total amount of blood product transfusion during surgery (unit) } \\
\hline Packed red blood cell & -0.123 & 0.885 & $0.841-0.931$ & $<0.001$ & & & & \\
\hline Fresh frozen plasma & -0.224 & 0.799 & $0.739-0.864$ & $<0.001$ & -0.163 & 0.85 & $0.774-0.933$ & 0.001 \\
\hline Platelet concentrate & -0.123 & 0.884 & $0.824-0.948$ & 0.001 & & & & \\
\hline Single donor platelet & -0.172 & 0.842 & $0.689-1.029$ & 0.093 & & & & \\
\hline Cryoprecipitate & -0.563 & 0.569 & $0.372-0.872$ & 0.01 & & & & \\
\hline \multicolumn{9}{|l|}{ Average of $A B G A$ factors during entire surgery } \\
\hline Hemoglobin $\left(\mathrm{g} \cdot \mathrm{dL}^{-1}\right)$ & 0.609 & 1.838 & $1.479-2.285$ & $<0.001$ & & & & \\
\hline $\mathrm{SaO}_{2}(\%)$ & -0.313 & 0.731 & $0.508-1.051$ & 0.091 & & & & \\
\hline \multicolumn{9}{|l|}{ Donor-graft findings } \\
\hline Graft-recipient weight ratio & -1.028 & 0.358 & $0.167-0.766$ & 0.008 & & & & \\
\hline Total graft ischemic time (min) & -0.011 & 0.989 & $0.983-0.995$ & $<0.001$ & & & & \\
\hline
\end{tabular}

Abbreviations: $\mathrm{Cl}$ confidence interval, $A B G A$ arterial blood gas analysis

at the end of surgery). Another LT study suggested that the possibility of early extubation (within $3 \mathrm{~h}$ after surgery) was affected by intraoperative blood transfusion volume, vital organ function (i.e., kidney, heart, and lung), and hepatic encephalopathy, but early extubation did not correlate with patient age or severity of liver disease (i.e., United Network for Organ Sharing [UNOS] status and Child-Pugh classification) [15].

This study had some limitations. First, we were unable to investigate muscular strength because of the retrospective study design. GS was considered a useful proxy for muscular strength and was related to certain pulmonary 
Table 4 Comparison of postoperative outcomes between the conventional and immediate extubation groups

\begin{tabular}{|c|c|c|c|}
\hline Group & $\begin{array}{l}\text { Conventional } \\
\text { extubation }\end{array}$ & $\begin{array}{l}\text { Immediate } \\
\text { extubation }\end{array}$ & $p$ \\
\hline$n$ & 154 & 101 & \\
\hline Hospital stay (day) & $23(21-31)$ & $23(21-31)$ & 0.53 \\
\hline $\begin{array}{l}\text { Intensive care unit } \\
\text { stay (day) }\end{array}$ & $7(6-8)$ & $7(5-7)$ & 0.008 \\
\hline $\begin{array}{l}\text { Ventilator support } \\
\text { duration (min) }\end{array}$ & $524(225-764)$ & $0(0-0)$ & $<0.001$ \\
\hline Re-intubation & $10(6.5 \%)$ & $3(3.0 \%)$ & 0.211 \\
\hline Pneumonia & $26(16.9 \%)$ & $4(4.0 \%)$ & 0.002 \\
\hline $\begin{array}{l}\text { Early allograft } \\
\text { dysfunction }\end{array}$ & $26(16.9 \%)$ & $2(2.0 \%)$ & $<0.001$ \\
\hline
\end{tabular}

Values are expressed as medians (with interquartile range) or numbers (with $\%$ proportion)

parameters in previous studies [29, 35]. Second, we only analyzed factors associated with OR extubation in male LDLT patients because there are differences in muscle size and strength between the sexes [6,40]; therefore, further studies that include female LDLT patients are needed. The effect of sex-specific muscular features on recovery of respiratory ability in patients with ESLD immediately after surgery would be an interesting topic for study [40]. Third, we were unable to investigate the relationship between age-related core muscle loss and the possibility of immediate extubation in the OR, because our cirrhotic patients were in their late $40 \mathrm{~s}$ and $50 \mathrm{~s}$. Because aging influences muscle strength and mass, an age-specific study of cirrhotic patients is required. Fourth, although there were no significant differences in the OR extubation rates among attending transplant anesthesiologists, there may be differences in OR extubation methods, because there is no consensus on the specific OR extubation criteria that should be applied for LDLT patients. Further studies that use a standardized protocol for OR extubation are needed. Finally, there were some differences in preoperative and/ or intraoperative conditions between the two groups, so the possibility of selection bias was not totally excluded. Therefore, further prospective matched studies are required to determine whether OR extubation has positive effects on postoperative outcomes, and whether the PMI can stand as an independent major parameter to determine immediate extubation in the OR after LT surgery.

\section{Conclusions}

Immediate tracheal extubation in the OR is safe and beneficial as part of a rapid recovery pathway after elective LDLT. However, as respiratory failure can occur postoperatively, it is important to accurately identify LDLT patients who are eligible for immediate extubation in the OR. Our study could improve the accuracy of prediction of immediate post-transplant extubation in the OR by introducing preoperative PMI into predictive models of patients who underwent elective LDLT. Eventually, a predictive model of early extubation in the OR, including preoperative levels of PMI and intraoperative hemodynamic factors (i.e., the use of CRRT, the development of significant PRS and a requirement for a large FFP transfusion), may help transplant clinicians to determine which patients are suitable for successful immediate OR extubation, and prevent inadequate ventilator care and unnecessary ICU administration after elective LDLT.

\section{Additional files}

Additional file 1: Comparison of $\mathrm{OR}$ extubation rates among five anesthesiologists. (DOCX $20 \mathrm{~kb}$ )

Additional file 2: Comparison of PMI between patients with and without sarcopenic features. (DOCX $17 \mathrm{~kb}$ )

Additional file 3: Correlation of preoperative psoas muscle index with spirometry parameters. (DOCX $18 \mathrm{~kb}$ )

\section{Abbreviations}

BMl: Body mass index; BNP: Brain natriuretic peptide; CT: Computed tomography; DM: Diabetes mellitus; ESLD: End-stage liver disease; FFP: Fresh frozen plasma; GWRW: Graft-recipient weight ratio; HBP: Systemic hypertension; ICU: Intensive care unit; INR: International normalized ratio; LDLT: Living donor liver transplantation; LT: Liver transplantation; MELD: Model for end-stage liver disease; OR: Operating room; PC: Platelet count; PMA: Psoas muscle area; PMI: Psoas muscle index; PRBCs: Packed red blood cells; PRS: Post-reperfusion syndrome; SDP: Single donor platelet

\section{Acknowledgments}

The authors wish to acknowledge the financial support of the Catholic Medical Center Research Foundation made in the program year of 2013.

\section{Authors' contributions}

MSC and SHH designed the study, wrote the manuscript, and analyzed and interpreted the data. JWK collected the data. JYJ, HJC, HSC, CSP and JHC collected the data and provided critical comments. All authors revised the manuscript critically for important intellectual content. All authors read and approved the final manuscript.

\section{Funding}

The financial support of the Catholic Medical Center Research Foundation made in the program year of 2013. The statistical analysis was supported by the fund.

\section{Availability of data and materials}

The datasets used and/or analyzed during this study are available from the corresponding author on reasonable request.

\section{Ethics approval and consent to participate}

The Institutional Review Board of Seoul St. Mary's Hospital Ethics Committee approved this study for LDLT recipients (KC18RESI0205) on April 13, 2018. and it was performed according to the principles of the Declaration of Helsinki. The requirement for informed consent was waived due to the retrospective study design.

Consent for publication

Not applicable.

\section{Competing interests}

The authors declare that they have no competing interests.

\section{Author details}

'Department of Anesthesiology and Pain medicine, Seoul St. Mary's Hospital, College of Medicine, The Catholic University of Korea, 222, Banpo-daero, 
Seocho-gu, Seoul 06591, Republic of Korea. ${ }^{2}$ Department of Radiology, Seoul St. Mary's Hospital, College of Medicine, The Catholic University of Korea, Seoul, Republic of Korea. ${ }^{3}$ Department of Surgery, Seoul St. Mary's Hospital, College of Medicine, The Catholic University of Korea, Seoul, Republic of Korea.

Received: 5 April 2019 Accepted: 5 June 2019

Published online: 28 June 2019

\section{References}

1. Kaido T, Ogawa K, Fujimoto Y, Ogura Y, Hata K, Ito T, et al. Impact of sarcopenia on survival in patients undergoing living donor liver transplantation. Am J Transplant. 2013:13:1549-56.

2. Englesbe MJ, Patel SP, He K, Lynch RJ, Schaubel DE, Harbaugh C, et al. Sarcopenia and mortality after liver transplantation. J Am Coll Surg. 2010;211:271-8

3. Chae MS, Moon KU, Jung JY, Choi HJ, Chung HS, Park CS, et al. Perioperative loss of psoas muscle is associated with patient survival in living donor liver transplantation. Liver Transpl. 2018;24:623-33.

4. Durand F, Buyse S, Francoz C, Laouenan C, Bruno O, Belghiti J, et al. Prognostic value of muscle atrophy in cirrhosis using psoas muscle thickness on computed tomography. J Hepatol. 2014;60:1151-7.

5. Kahn J, Wagner D, Homfeld N, Muller H, Kniepeiss D, Schemmer P. Both sarcopenia and frailty determine suitability of patients for liver transplantation-a systematic review and meta-analysis of the literature. Clin Transpl. 2018;32:e13226.

6. Biancofiore G, Tomescu DR, Mandell MS. Rapid recovery of liver transplantation recipients by implementation of fast-track care steps: what is holding us Back? Semin Cardiothorac Vasc Anesth. 2018;22:191-6.

7. Lai JC. Defining the threshold for too sick for transplant. Curr Opin Organ Transplant. 2016;21:127-32

8. van Vugt JLA, Alferink LJM, Buettner S, Gaspersz MP, Bot D, Darwish Murad $S$, et al. A model including sarcopenia surpasses the MELD score in predicting waiting list mortality in cirrhotic liver transplant candidates: a competing risk analysis in a national corhot. J Hepatol. 2017;68:707-14.

9. Stock PG, Payne WD. Liver transplantation. Crit Care Clin. 1990;6:911-26.

10. Cohen J, Loewinger J, Hutin K, Sulkes J, Zelikovski A, Singer P. The safety of immediate extubation after abdominal aortic surgery: a prospective, randomized trial. Anesth Analg. 2001;93:1546-9 table of contents.

11. Lanuti M, de Delva PE, Maher A, Wright CD, Gaissert HA, Wain JC, et al. Feasibility and outcomes of an early extubation policy after esophagectomy. Ann Thorac Surg. 2006;82:2037-41.

12. Mandell MS, Lezotte D, Kam I, Zamudio S. Reduced use of intensive care after liver transplantation: influence of early extubation. Liver Transpl. 2002;8:676-81.

13. Aniskevich S, Pai SL. Fast track anesthesia for liver transplantation: review of the current practice. World J Hepatol. 2015;7:2303-8.

14. Biancofiore $G$, Bindi ML, Romanelli AM, Boldrini A, Bisa M, Esposito M, et al. Fast track in liver transplantation: 5 years' experience. Eur J Anaesthesiol. 2005;22:584-90.

15. Biancofiore G, Romanelli AM, Bindi ML, Consani G, Boldrini A, Battistini M, et al. Very early tracheal extubation without predetermined criteria in a liver transplant recipient population. Liver Transpl. 2001;7:777-82.

16. Glanemann M, Langrehr J, Kaisers U, Schenk R, Muller A, Stange B, et al. Postoperative tracheal extubation after orthotopic liver transplantation. Acta Anaesthesiol Scand. 2001;45:333-9.

17. Mandell MS, Stoner TJ, Barnett R, Shaked A, Bellamy M, Biancofiore G, et al. A multicenter evaluation of safety of early extubation in liver transplant recipients. Liver Transpl. 2007;13:1557-63.

18. Skurzak S, Stratta C, Schellino MM, Fop F, Andruetto P, Gallo M, et al. Extubation score in the operating room after liver transplantation. Acta Anaesthesiol Scand. 2010;54:970-8.

19. Feltracco P, Carollo C, Barbieri S, Pettenuzzo T, Ori C. Early respiratory complications after liver transplantation. World J Gastroenterol. 2013; 19:9271-81.

20. Cash WJ, McConville P, McDermott E, McCormick PA, Callender ME, McDougall NI. Current concepts in the assessment and treatment of hepatic encephalopathy. Qjm. 2010;103:9-16.

21. Chae MS, Jeon YK, Kim DG, Na GH, Yi YS, Park CS. Cardiac tamponade due to Suprahepatic surgical exploration in liver Retransplantation: a case report. Transplant Proc. 2016;48:3181-5.
22. Chae MS, Koo JM, Park CS. Predictive role of intraoperative serum brain natriuretic peptide for early allograft dysfunction in living donor liver transplantation. Ann Transplant. 2016;21:538-49.

23. Practice guidelines for perioperative blood management: an updated report by the American Society of Anesthesiologists Task Force on perioperative blood management*. Anesthesiology. 2015;122:241-75. https://doi.org/10. 1097/ALN.0000000000000463.

24. Hong SH, Park CS, Jung HS, Choi H, Lee SR, Lee J, et al. A comparison of intra-operative blood loss and acid-base balance between vasopressor and inotrope strategy during living donor liver transplantation: a randomised, controlled study. Anaesthesia. 2012;67:1091-100.

25. Baek SD, Jang M, Kim W, Yu H, Hwang S, Lee SG, et al. Benefits of intraoperative continuous renal replacement therapy during liver transplantation in patients with renal dysfunction. Transplant Proc. 2017:49:1344-50.

26. Douthitt L, Bezinover D, Uemura T, Kadry Z, Shah RA, Ghahramani N, et al. Perioperative use of continuous renal replacement therapy for orthotopic liver transplantation. Transplant Proc. 2012;44:1314-7.

27. Lentine KL, Kasiske BL, Levey AS, Adams PL, Alberu J, Bakr MA, et al. KDIGO clinical practice guideline on the evaluation and Care of Living Kidney Donors. Transplantation. 2017;101:S1-s109.

28. Hilmi I, Horton CN, Planinsic RM, Sakai T, Nicolau-Raducu R, Damian D, et al. The impact of postreperfusion syndrome on short-term patient and liver allograft outcome in patients undergoing orthotopic liver transplantation. Liver Transpl. 2008:14:504-8.

29. Shirai H, Kaido T, Hamaguchi Y, Yao S, Kobayashi A, Okumura S, et al. Preoperative low muscle mass has a strong negative effect on pulmonary function in patients undergoing living donor liver transplantation. Nutrition. 2018:45:1-10.

30. Izumi T, Watanabe J, Tohyama T, Takada Y. Impact of psoas muscle index on short-term outcome after living donor liver transplantation. Turk J Gastroenterol. 2016;27:382-8.

31. Olthoff KM, Kulik L, Samstein B, Kaminski M, Abecassis M, Emond J, et al Validation of a current definition of early allograft dysfunction in liver transplant recipients and analysis of risk factors. Liver Transpl. 2010;16:943-9.

32. Collins GS, Reitsma JB, Altman DG, Moons KG. Transparent reporting of a multivariable prediction model for individual prognosis or diagnosis (TRIPOD): the TRIPOD statement. Br J Surg. 2015:102:148-58.

33. Martin DS, Grocott MP. Oxygen therapy in critical illness: precise control of arterial oxygenation and permissive hypoxemia. Crit Care Med. 2013;41:423-32.

34. Miller CM, Quintini C, Dhawan A, Durand F, Heimbach JK, Kim-Schluger HL, et al. The international liver transplantation society living donor liver transplant recipient guideline. Transplantation. 2017;101:938-44.

35. Shirai H, Kaido T, Hamaguchi Y, Kobayashi A, Okumura S, Yao S, et al. Preoperative low muscle mass and low muscle quality negatively impact on pulmonary function in patients undergoing hepatectomy for hepatocellular carcinoma. Liver Cancer. 2018;7:76-89.

36. Yamashita M, Kamiya K, Matsunaga A, Kitamura T, Hamazaki N, Matsuzawa $\mathrm{R}$, et al. Prognostic value of psoas muscle area and density in patients who undergo cardiovascular surgery. Can J Cardiol. 2017;33:1652-9.

37. Wagner D, DeMarco MM, Amini N, Buttner S, Segev D, Gani F, et al. Role of frailty and sarcopenia in predicting outcomes among patients undergoing gastrointestinal surgery. World J Gastrointest Surg. 2016;8:27-40.

38. Piriyapatsom A, Williams EC, Waak K, Ladha KS, Eikermann M, Schmidt UH. Prospective observational study of predictors of re-intubation following Extubation in the surgical ICU. Respir Care. 2016;61:306-15.

39. Montano-Loza AJ. Clinical relevance of sarcopenia in patients with cirrhosis. World J Gastroenterol. 2014;20:8061-71.

40. Miller AE, MacDougall JD, Tarnopolsky MA, Sale DG. Gender differences in strength and muscle fiber characteristics. Eur J Appl Physiol Occup Physiol. 1993;66:254-62

\section{Publisher's Note}

Springer Nature remains neutral with regard to jurisdictional claims in published maps and institutional affiliations. 